\title{
A select committee to be kept
}

WITHIN a period of weeks rather than months the UK House of Commons is likely to start discussing changes in procedure, and high on the list of priorities will be a re-organisation of the select committee structure. There is a wide measure of support in parliament for the re-aligning of committees along ministerial lines, and were this to come about the Select Committee on Science and Technology would be dishanded; scientific issues would then be the concern of, at the least, the select committees on agriculture; defence; education, science and the arts; energy; environment; industry; and social services. Professors Ziman and Denbigh recently expressed the view of the Council for Science and Society that this would be a retrograde step (10 May, p 100).

This is a view which will be widely shared by scientists and technologists. The present committee has come in for its fair share of criticism from us and others in the past, but at least it has provided a fairly effective way by which the communities of science and technology could make contact with parliament, in an almost totally non-partisan way, on matters of concern. In none of the proposed new committees will scientists find their interests and worries given anything like the same attention-least of all in the education, science and arts committee, where education will surely swamp everything else.

The scientific and technological community, almost by its very nature, has never had more than a handful of its number in the Commons. During its time, however, the select committee has turned up several non-scientists who have taken an active and highly intelligent interest in scientific matters; in the new order there is unlikely to be any incentive for such people to come foward.

Finally, the assumption made in the new scheme is that the way the government divides its ministerial responsibilities is the way that major national issues divide. This is simply not true in the scientific and technological field. Who would look at genetic manipulation? The impact of microprocessors? Support for innovation? Scientific manpower problems? Training for the engineering profession? Climatic change? These are all matters in which parliamentarians ought to be informed. And none of them falls neatly into one department's remit.

\section{Elitist patronage-and rightly so}

FIVE years ago the German pharmaceutical company $\mathbf{C} . \mathbf{H}$. Boehringer Sohn of Ingelheim invited a group of biologists, medical researchers, and philosophers to spend a few days together in a well-appointed Schloss far from the pressures of colleagues, students and telephones. The group brooded on the question of creativity, and a report of the deliberations was later published (The creative process in science and medicine edited by Hans Krebs and Julian Shelley; Excerpta Medica).

The indefatigable Dr Shelley, Boehringer's Director of Clinical Investigation, has just stage-managed a second symposium with a broad interdisciplinary sweep. As if the first of them were not wide-ranging enough, the second was entitled 'Structure in Science and Art', and this time the biologists and philosophers were joined by an architect, a professor of English, two composers, a novelist, three physicists, a concert pianist and an art historian. This heady brew resembled nothing so much as a High Table of High Tables in the Oxbridge tradition, except, of course, that with a battery of microphones and an army of typists waiting to transcribe every slightest remark, conversation was considerably more elevated than standard High Table fare concerning the foibles of students, the price of books and the run-down condition of the college gardens.

This is no place to try to summarise the presentations and discussions, which roamed over perception, the ob- server in the universe, structuralism in the novel, D'Arcy Thompson's mathematical analysis of form, Breughel's 'Icarus', Schoenberg's piano music and much else besides. But it is appropriate to ask whether at the end of the day any threads, however tenuous, had been laid across the yawning chasm between the sciences and the arts. Does 'structure' offer any common ground--does, for instance, appreciation of the structure of a Mozart concerto help those looking for structure in biological molecules? On the face of it, no.

Those who read the proceedings of this symposium in the hope of seeing new lines of thought emerge, spanning the disciplines, will almost certainly be disappointed. But sensitivity to a wide range of subjects probably does help to enrich work in one's own particular discipline. And occasions such as this symposium do help to heighten that sensitivity of those fortunate participants.

It is a commonplace to say of a conference that the real work was done outside the formal sessions. In this case, however, there is little doubt that this was true; the new contacts, the informal conversations will count for more than what was actually said to the microphones. Mercifully the sponsors seem to appreciate this, and look for no agreed conclusions, no statement to the world out of it all. It is enlightened patronage, of an elitist sort that few dare to pursue these days. 